\title{
A case report of recurrent corneal erosion post-blepharoplasty
}

Rubamalar Gunatheesan, Yean Yaw Choong

The Tun Hussein Onn National Eye Hospital, Petaling Jaya, Malaysia

\section{Abstract}

Our purpose is to report a case of recurrent corneal erosion post Asian blepharoplasty or double-eyelid surgery. The patient was initially treated with bandage contact lens, lubricants, and mild steroids with temporary improvement. Complete resolution of symptoms was achieved only following suture removal. Upper eyelid eversion with proper exploration of the fornix is key to identify hidden sutures.

Keywords: recurrent corneal erosion, post-blepharoplasty

Correspondence: Gunatheesan, Rubamalar MBBS, FRCOphth, The Tun Hussein Onn National Eye Hospital, Lot 2, Lorong Utara (B), Pjs 52, 46200 Petaling Jaya, Selangor, Malaysia.

E-mail: ruba.gunatheesan@gmail.com 


\section{Laporan kes hakisan kornea berulang selepas blepharoplasty}

\section{Abstrak}

Tujuan kami adalah untuk melaporkan kes hakisan kornea berulang selepas pembedahan blepharoplasti Asia atau kelopak mata berganda. Pesakit pada awalnya dirawat dengan kanta lekap, pelincir, dan steroid ringan melalui penyembuhan yang sementara sahaja. Kesembuhanlengkap semua gejala hanya dicapai setelah benang jahitan dibuang. Eversi kelopak mata dengan sempurna pada bahagian atas dengan pemeriksaan fornik yang betul adalah kunci untuk mengenal pasti wujudnya jahitan tersembunyi.

Kata kunci: hakisan kornea berulang, pos-blepharoplasti

\section{Introduction}

Recurrent corneal erosion (RCE) syndrome is a common disorder worldwide. The main presenting complaint is sudden onset of mild to severe eye pain (especially on awakening), redness, photophobia, and tearing. Episodes may last from seconds to days. ${ }^{1}$ Ocular trauma, corneal dystrophies such as epithelial basement membrane dystrophy, Meesmann dystrophy, Reis-Bücklers' corneal dystrophy, lattice degeneration, and granular dystrophy, as well as contact lens wear can result in RCE syndrome. ${ }^{2,3}$ Less common causes include non-inherited corneal conditions such as Salzmann's nodular degeneration, band keratopathy, herpes infections, ocular rosacea, lagophthalmos, keratoconjunctivitis sicca, bullous keratopathy, and systemic diseases such as diabetes mellitus and epidermolysis bullosa. ${ }^{4}$

A retrospective review by Reidy et $a l .^{5}$ of 104 patients with RCE identified trauma $(45 \%)$ as the most common cause, followed by epithelial basement membrane dystrophy (29\%). Of these patients, $17 \%$ had both trauma and epithelial basement membrane dystrophy. More than $87 \%$ of all RCE occurred on the inferior third of the cornea.

RCE has also been seen postoperatively in patients treated for refractive errors, cataracts or corneal pathologies needing keratoplasty. However, RCE induced by late suture exposure from prior blepharoplasty has been rarely reported. Here, we describe a case of RCE syndrome in a female patient, 2 years after double-eyelid surgery. She presented with corneal erosion in the upper nasal quadrant that recurred soon after treatment with topical lubricants, mild steroids, and bandage contact lens. 


\section{Case report}

A 26-year-old woman presented with redness in her right eye for 1 month. She complained of decreased visual acuity and eye pain. She had previously seen three other ophthalmologists for the same condition and was treated as a case of idiopathic RCE and herpetic keratitis. However, her condition did not improve. She had worn contact lens for several years. Her past medical history was not significant, with no diabetes or known allergies. The patient denied any recent ocular trauma preceding her symptoms.

At presentation, her best-corrected visual acuity (BCVA) was counting fingers (CF) in the right eye and 6/6 in the left eye. The right eye showed a 2.8 $x 4.5 \mathrm{~mm}$ corneal epithelial defect with rough edges and surrounding sloughy corneal epithelium. There was associated mild subepithelial haze but no stromal infiltrate. The epithelial defect was located at the superior nasal region of the corneal surface. It was slightly off-centre, involving the visual axis (Fig. 1). On staining with fluorescein, the epithelial defect was clearly evident (Fig. 2). The anterior chamber was deep and quiet. There was no evidence of corneal dystrophy in either eye. Examination of the left eye was completely normal. Having a high index of suspicion for a retained upper lid foreign body given the unusual location of the epithelial defect and its recurrent nature, eyelid eversion was performed. However, no foreign body was evident at this stage.

The patient was treated with bandage contact lens and commenced on topical antibiotic eye drops three times per day as well as preservative-free topical lubricants every 2 hours. On review 2 days later, the patient was symptomatically better. The epithelial defect was healing, and was less than half the size at presentation, with well-defined edges. Treatment was continued and low-potency topical steroid eye drops twice daily were added. On follow-up 6

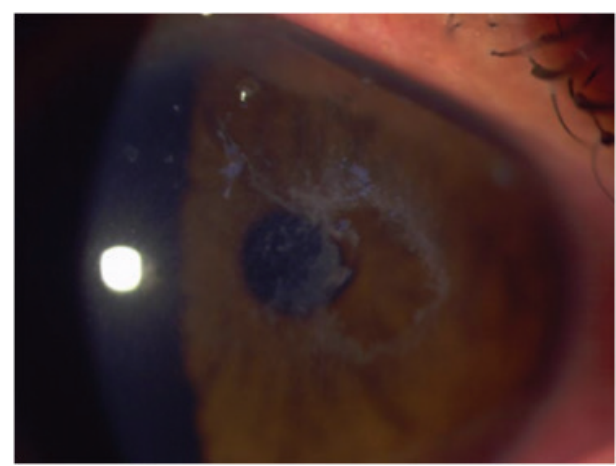

Fig. 1. Corneal epithelial defect as seen at initial presentation prior to fluorescein staining.

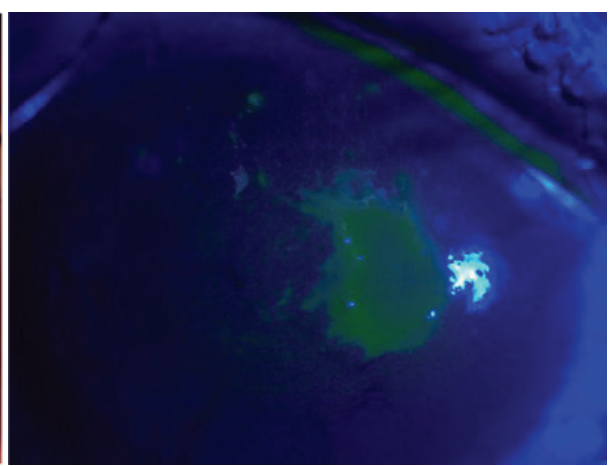

Fig. 2. Corneal epithelial defect as seen at initial presentation with fluorescein staining. 
days after initial presentation, her BCVA had improved to 6/9 in the right eye. On slit-lamp examination, the epithelial defect had healed (Fig. 3) with the presence of negative staining and some superficial punctate keratopathy (Fig.4). The bandage contact lens was removed. The patient continued treatment with similar topical eye drops and a topical lubricant eye gel was added at night. She was then discharged from further follow-up but was advised to return if symptoms recurred.

The patient presented again 9 days later with similar symptoms of pain, tearing and photophobia in her right eye for 3 days. Her BCVA was counting fingers, pinhole $6 / 18$ in the right eye. On examination, she was found to have an epithelial defect over the same region as her previous corneal abrasion, which stained with fluorescein. A bandage contact lens was reapplied. The patient was commenced on topical antibiotic eye drops three times a day, topical steroid eye drops daily, and topical preservative-free artificial tears every 2 hours in the right eye.

Having suspected a retained upper lid foreign body, we further questioned the patient specifically about double-eyelid surgery. Only then she divulged her history of previous Asian blepharoplasty two years prior. The patient had not voluntarily informed us about undergoing eyelid surgery in the past visits. This new information led us to strongly suspect the presence of a buried upper eyelid suture. Hence, on follow-up, once her pain had subsided, we repeated upper eyelid eversion at the slit lamp. This time, the patient was made to look in extreme downgaze and the superior conjunctival fornix was explored with a suture-tying forceps. At this point, a tiny portion of the tip of the retained nylon suture was visualized over the superior fornix (Fig. 5). Thorough exploration of the superior conjunctival fornix enabled us to identify the whole hidden suture. The nylon suture was then exposed fully with the forceps, cut with scissors, and removed (Figs. 6 and 7).

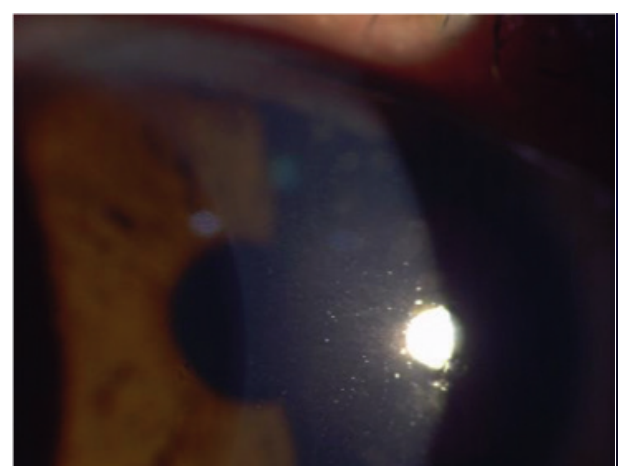

Fig. 3. Slit-lamp examination of the corneal epithelial defect 2 days after initial review

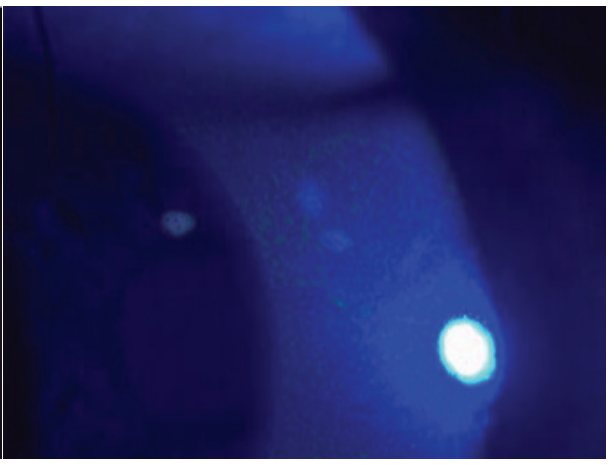

Fig. 4. Slit-lamp examination of corneal epithelial defect 2 days after initial review, with fluorescein staining. 


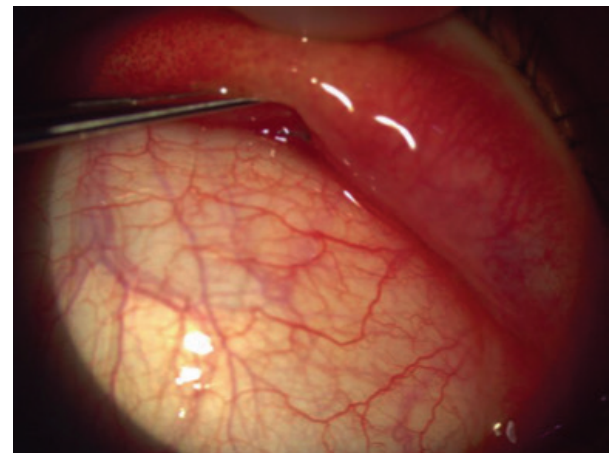

Fig. 5. Examination of the upper fornix with double eyelid eversion revealing hidden nylon suture

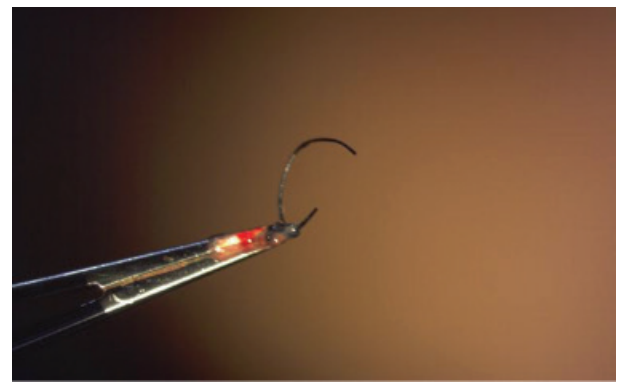

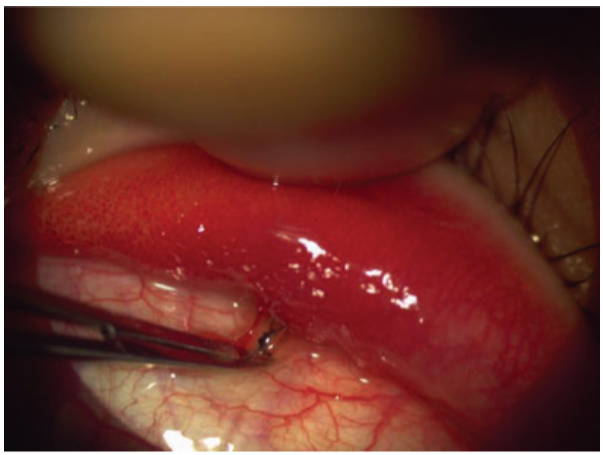

Fig. 6. Hidden nylon suture exposed at slit lamp with forceps.

Fig. 7. Removed nylon suture.

Post-suture removal, the epithelial defect recovered fully and her BCVA returned to $6 / 6$ in both eyes. She no longer had symptoms of RCE 2 years after the removal of the suture. The patient was very happy with the outcome.

\section{Discussion}

RCE typically occurs in eyes following abrading injuries, eyes with corneal dystrophies such as epithelial basement membrane dystrophy and lattice dystrophy, or in eyes with previous ocular surgery such as refractive surgery, cataract surgery, or corneal transplantation. ${ }^{6}$ The majority of cases will respond to simple conservative medical management with topical lubricants, topical antibiotics, and soft bandage contact lenses. This is a case report of an unusual cause of RCE that occurred post-double-eyelid blepharoplasty and remained persistent with conservative medical treatment. 
The majority of acute corneal erosions in a prospective randomized controlled trial by Hykin et al. occurred wholly within the lower half of the cornea, irrespective of aetiology. This can be attributed to upper eyelid movement across this region of the ocular surface and local tear film drying, which most likely disrupts the corneal surface at this site. ${ }^{7}$ Patients with tarsal conjunctival foreign bodies can present with linear vertical epithelial defects from the movement of the foreign body during blinking. The site and nature of corneal erosions provide clues to diagnosis. In our patient, the corneal erosion was noted to be off-centre, in the superior half of the cornea, which was unusual. This led to the suspicion of an upper eyelid foreign body and was followed up with eyelid eversion. However, lid eversion alone was not sufficient to identify the hidden suture. Thorough exploration of the superior conjunctival fornix revealed the hidden offending suture.

Normal adhesion of the corneal epithelium is maintained by structures known as adhesion complexes, which are composed of hemidesmosomes, the lamina densa and lamina lucida of the basement membrane, anchoring fibrils, laminin, fibronectin, and type IV as well as VII collagen. ${ }^{8}$ In RCE, reattachment of the corneal epithelium appears to be faulty following an initial abrasion. A variety of adhesion complex defects have been observed in RCE including reduplication of basement membrane, loculation of connective tissues, and absence of basement membrane and hemidesmosomes. ${ }^{9}$ Apart from pain relief, the aim of RCE management is to promote re-epithelialisation and re-establishment of a competent basement membrane complex. The healed epithelium needs to remain intact for a sufficient length of time to enable the re-formation of adhesion complexes. ${ }^{10}$ In our patient, the nylon suture from the prior blepharoplasty prevented the establishment of a healthy basement membrane for long-term healing. The bandage contact lens acted as a mechanical barrier in protecting the corneal epithelium from the offending suture. However, definitive treatment involved the discovery and removal of the offending upper eyelid nylon suture.

Double-eyelid blepharoplasty is commonly performed in Asian countries. The buried suture technique is done to avoid visible surgical scars. ${ }^{11}$ The incision technique, on the other hand, is performed through the external incision and does not involve the palpebral conjunctiva. The buried suture technique is preferred to the incision method as the patient can avoid visible surgical scars and can be more easily revised. ${ }^{12}$ However, there are substantial risks involved with this technique, such as chronic inflammation of the conjunctival plate and risks associated with a retained foreign body including suture granuloma, ocular discomfort, and pulling sensation. Here we have illustrated another complication of blepharoplasty using the buried suture technique, namely late suture exposure and RCE. 


\section{Conclusion}

Blepharoplasty-induced RCE due to exposure of buried upper eyelid sutures is rarely reported. Late suture exposure needs to be considered in patients with a history of blepharoplasty with RCE. A good history and a high index of suspicion of upper eyelid foreign body, together with proper eyelid eversion and thorough exploration of the fornices is imperative to identify these hidden sutures.

\section{References}

1. Xu Kunyong, Kam Ka Wai, Young Alvin L, Jhanji Vishal. The Asia-Pacific Journal of Ophthalmology. 2012;1(56):349-354.

2. Nanba H, Mimura T, Mizuno Y, et al A. Clinical course and risk factors of recurrent corneal erosion. Medicine. 2019;98(16)

3. Bron AJ, Burgess SE. Inherited recurrent corneal erosion. Trans Ophthalmol Soc UK. 1981;101:239243.

4. Brown N, Bron AJ. (Recurrent erosion of the cornea. Br J Ophthalmol 1976,60:84-96.

5. Reidy JJ, Paulus MP, Gona S. Recurrent erosions of the cornea: epidemiology and treatment. Cornea. 2000;19:767-771.

6. Darby DM, Syed AH, Nathaniel LS, Michael WS. Recurrent corneal erosion: A comprehensive review. Clin Ophthalmol. 2019; 13: 325-335.

7. Hykin PG, Foss AE, Pavesio C, Dart JK. The natural history and management of recurrent corneal erosion: a prospective randomised trial. Eye (Lond). 1994;8(Pt 1):35-40. doi:10.1038/eye.1994.6.

8. Gipson IK. Adhesive mechanisms of the corneal epithelium. Acta Ophthalmol. 1992;202(Suppl):1317.

9. Rodrigues MM, Fine BS, Laibson PR, Zimmerman LE. Disorders of the corneal epithelium. A clinicopathologic study of dot, geographic, and fingerprint patterns. Arch Ophthalmol. 1974;92:475-482.

10. Ramamurthi S, Rahman M, Dutton, G, et al. Pathogenesis, clinical features and management of recurrent corneal erosions. Eye 2006;20:635-644. doi:10.1038/sj.eye.6702005.

11. Chen WPD. Suture ligation methods. In: Chen WPD, editor. Asian Blepharoplasty and the Eyelid Crease. 3rd ed. Philadelphia: Elsevier; 2016. pp. 51-66.

12. Mizuno T. Treatment of Suture-related Complications of Buried-suture Double eyelid Blepharoplasty in Asians. J Plast Reconstr Aesthet Surg. 2016;4(8):e839.

13. Lelli GJ Jr, Lisman RD. Blepharoplasty complications. Plast Reconstr Surg. 2010;125(3):1007-1017 